\title{
Profitability of Banks in Lebanon: Some Theoretical and Empirical Results
}

\author{
Samih Antoine Azar ${ }^{1}$, Ali Bolbol ${ }^{2} \&$ Alexandre Mouradian ${ }^{3}$ \\ ${ }^{1}$ Faculty of Business Administration \& Economics, Haigazian University, Beirut, Lebanon \\ ${ }^{2}$ Economic Advisor, Blominvest Bank, Beirut, Lebanon \\ ${ }^{3}$ Head of Investor Relations, Blominvest Bank, Beirut, Lebanon \\ Correspondence: Samih Antoine Azar, Professor, Faculty of Business Administration \& Economics, Haigazian \\ University, Mexique Street, Kantari, Beirut, Lebanon. Tel: 961-1-349-230. E-mail: samih.azar@haigazian.edu.lb
}

Received: April 26, 2016

Accepted: May 5, 2016

Online Published: June 25, 2016

doi:10.5539/ijef.v8n7p233

URL: http://dx.doi.org/10.5539/ijef.v8n7p233

\begin{abstract}
The paper, instead of relying on ad hoc measures, derives a simple theoretical model for the income of a commercial bank. This model identifies eight internal exogenous factors to the profitability of these banks. A total panel of 39 banks over the twelve-year period 2003-2014 is studied. The dependent variable is taken to be the return on average total assets (ROAA). The estimation procedure is through panel least squares. Fixed effects and random effects are considered. The results support the cross section fixed effects model, which brings to light the heterogeneity of banks in Lebanon. Four out of the eight factors are found to be statistically highly significant, explaining about 50\% of the variation in ROAA. These are: the interest rate spread, the capital adequacy ratio, the cost to income ratio, and the ratio of non-interest income to total assets. Dynamics are included in the model by adding to the regressors the first lag of the dependent variable. This makes for different short run and long run impacts, with the latter found to be higher than the former as economic theory postulates. Among other recommendations banks are advised to diversify their income towards more wealth management and investment banking, to pay particular attention to their traditional source of income, which is the interest rate spread between loans and deposits, and to manage carefully their cost structure.
\end{abstract}

Keywords: commercial banks, profitability, ROAA, internal factors, Lebanon, panel least squares

\section{Introduction}

At least since the early 1990s, Lebanese banks have been on the rebound. After the devastating civil war of 1975-1990, they have managed to re-capitalize, consolidate, and re-invent themselves as the most crucial sector in the economy. They have also been guided by an effective regulatory system at the Central Bank of Lebanon. But the past twenty five years have not been easy, since the country has remained to this day mired in frequent economic and political shocks. Paradoxically, this has strengthened Lebanese banks, in the sense that it enabled them to hone their skills in managing under conditions of high uncertainty and it drove them to expand in the region so as to diversify risk and revenue. Of course, that was not cost free. It led Lebanese banks to become more conservative, something that has elevated their costs and dented their profitability, since their relative profitability rates ended up lower than the regional averages (Note 1). In terms of the return on average assets, ROAA, and the return on average equity, ROAE, Lebanese rates stood at $1 \%$ and $11 \%$ respectively, against corresponding rates of $1.6 \%$ and $12.5 \%$ for the region (Note 2). However, that has also made Lebanon a destination for safe and responsible banking, helping to increase its deposit base to close to 300\% of GDP (Note $3)$.

It is interesting, then, to see how Lebanese banks have maintained their steady-albeit relatively lower -profitability and to check what its major determinants are, especially at this time when prolonged instabilities are starting to leave their scars on Lebanese banks' performance (Note 4). The literature on bank profitability is extensive, but has not yet made a noticeable inroad into Lebanese banking. A brief look at this literature reveals that it is centered on three sets of determinants: internal or bank-specific (i.e. capital adequacy, credit risk, bank size, operational efficiency, liquidity, non-interest income); industry-specific (i.e. ownership, concentration); and external or macroeconomic (i.e. GDP growth, inflation, interest rates) (Note 5). The external determinants are the 
least problematic, since almost all evidence points rightly to a positive relation between its three variables and bank profitability (Note 6). The industry-specific determinants are a bit problematic, but only as far as ownership is concerned, since the evidence overwhelmingly finds that bank profitability and concentration are directly related. However, the uncertainty regarding bank ownership centers on foreign ownership not private ownership, the latter being almost always more profitable than public ownership. As to foreign ownership, the effect seems to depend on whether technological advantages of foreign banks outweigh their informational disadvantages in domestic markets or not. More problematic are the effects of internal determinants, and they primarily relate to capital adequacy, credit risk, and bank size. Well-capitalized banks could be losing in foregone higher interest, or could be reaping cost advantages due to their stronger financial position, with hence an uncertain impact on profitability. Higher credit risk could translate to larger returns, or alternatively to higher non-performing loans and provisions, such that its effect on profitability is indeterminate. Larger bank size could equally mean more scale economies or more scale diseconomies, and thus opposing impacts on profitability, but just as likely it could imply a non-linear relation between bank size and profitability (Note 7).

What about the limited evidence on Lebanese banks? It comes mainly in two strains, one relates profitability rates to a combination of the above set of variables, and the other relates net interest margin, NIM, to the same variables. Of the first strain, an early paper by Hakim and Neaime (2001) find ROAE to be negatively related to the capital adequacy ratio and positively related to credit risk, but unrelated to liquidity; whereas Peters et al (2004) find ROAA to have a positive relation with NIM but a negative one with bank size. As to the second strain, Saad and El-Moussawi (2012) find NIM to exhibit a positive relation with capitalization and bank size, but a negative relation with credit risk (Note 8); while Azar and Kouyoumijian (2016) arrive at similar results, but find additionally that NIM is negatively related to liquidity (Note 9).

Perhaps more importantly, what these few papers share is that they lack a theoretical model upon which to base these profitability results (Note 10). There is also no obvious delineation as to what constitutes exogenous and endogenous variables (Note 11). We will attempt to address those deficiencies in this short paper. We will do that by presenting a basic model of profit maximization for Lebanese banks, but one that recognizes the simple but profound fact that this is done under some constraints. These could be regulatory in nature like those that deal with capital adequacy and liquidity, and could be strategic in nature such as those that aim at diversification and risk control (Note 12).

In section 2, we present our basic model of constrained profit maximization, and derive a functional form that relates ROAA to a set of exogenous variables that capture the internal (and partly problematic) determinants of relative profitability. More specifically, in section 3 we estimate this model by regressing ROAA against 8 exogenous variables: net interest margin, cost-to-income, credit risk, capital adequacy, liquidity, provisions, non-performing loans, and non-interest income. The model is estimated over an unbalanced panel data comprising 39 commercial banks and stretching from 2003 to 2014, with 14 of the banks constituting the Alpha Group, the group of largest banks with deposits of $\$ 2$ billion or higher (Note 13). We employ three different formulations in the estimation process: panel with Ordinary Least Squares, panel with fixed cross section effects, and panel with random cross section effects. The best fit formulation is the panel with fixed cross section effects, reflecting the valid heterogeneity among commercial banks in Lebanon. In section 4, we evaluate the estimated results, and argue that only four variables are most significant and robust in the panel fixed cross section formulation: net interest margin, cost-to-income ratio, capital adequacy ratio, and the ratio of non-interest income to assets. And of these four variables, only the capital adequacy ratio carries a sign opposite to the one obtained in the theoretical model, namely a positive relation with ROAA. In section 5, we summarize the results and conclude that banks in Lebanon should focus on strengthening these four variables to enhance their sustained profitability.

\section{Basic Model}

We depart from the standard modeling of bank profitability that is frequently done on an ad hoc basis, and present below a small, basic model of the internal determinants of profits in Lebanese banks. In terms of balance sheet items, assets, A, are made up of liquidity, LIQ, plus investments, I, and Loans, L (Note 14); liabilities are represented by deposits, D; and shareholders' equity are composed of tier I and II capital, C. Given this simple but accurate balance sheet structure, the representative Lebanese bank maximizes the following net income function, $\Pi$ :

$$
\Pi=\left(r-r_{o}\right)(A-C)+N I I-\left(r-r_{o}\right) L I Q-\left(P^{*}-P\right)-\delta\left\{\left(r-r_{o}\right)(A-C)+N I I-\left(r-r_{o}\right) L I Q-\left(P^{*}-P\right)\right\}
$$

Subject to the following five constraints:

$$
C / \theta A \geq \alpha
$$




$$
\begin{gathered}
L I Q / A \geq \beta \\
P * / N P L \geq \vartheta \\
N P L / C \leq \omega \\
N I I / A \geq \psi
\end{gathered}
$$

Equation (1) defines net income as the difference between operational revenue and cost. Operational revenue is equal to: net interest income made on $\mathrm{A}$ less of $\mathrm{C}$, with $\mathrm{r}$ being the interest rate earned on $\mathrm{I}$ and $\mathrm{L}$ while $\mathrm{r}_{\mathrm{o}}$ is the interest rate paid on D as the main source of funding for Lebanese banks (Note 15); plus non-interest income, NII (Note 16); minus net interest income lost on holding LIQ; and minus the difference between the desired level of loan-loss provisions, $\mathrm{P}^{*}$, and the actual level, $\mathrm{P}$. As to operational cost, note that $\delta$ is the cost to income ratio, defined as operational cost divided by operational revenue. Hence, operational cost, $\mathrm{C}$, becomes: $\delta\left\{\left(\mathrm{r}-\mathrm{r}_{\mathrm{o}}\right)(\mathrm{A}\right.$ C) + NII - $\left(r-r_{0}\right)$ LIQ - $\left.\left(\mathrm{P}^{*}-\mathrm{P}\right)\right\}$.

Of course, net income is maximized subject to constraints, some are regulatory and some are imposed by management. The first of these constraints is given by equation (2), which reflects the capital adequacy ratio (CAR). This requirement as set by the Central bank of Lebanon (BdL) stipulates that the ratio of capital to risk-weighted assets, $\mathrm{C} / \theta \mathrm{A}$ - with $\theta$ being the risk weight - should be at least equal to $\alpha=12 \%$, in accordance to Basel III requirements. Equation (3) represents the liquidity constraint, and indicates that the ratio of primary liquidity to assets should at a minimum be equal to $\beta$, where $\beta$ is targeted at $30 \%$. This constraint is also strictly binding since the unstable economic and political environment necessitates that Lebanese banks remain highly liquid, a position strongly favored by BdL as well (Note 17). The third constraint given by equation (4) concerns the coverage of non-performing loans, NPL. It is BdL-driven, and favors adequate coverage of NPL by desired (specific and collective) loan-loss provisions, $\mathrm{P}^{*}$, at a ratio, $\vartheta$, that should at least be equal to $80 \%$ (Note 18 ). Equation (5) defines the fourth constraint, and it reflects the precautionary measure of not having NPL exceed a given percentage of C, preferably at $\omega=30 \%$ (Note 19). The last constraint captures management's desire for diversification towards untraditional banking activities. As presented in equation (6), it aims at having non-interest income as a fraction of assets be equal to $\psi$, the latter preferably set at a minimum of $0.4 \%$.

The constrained profit maximization given by equations (1)-(6) has six dependent variables (Note 20): A, C, $\mathrm{P}^{*}$, LIQ, NPL, and NII. The solution to these dependent variables should make them function of the following exogenous or independent variables: $\left(r-r_{0}\right), \delta, \theta, \alpha, \beta, \vartheta, \omega$, and $\psi$. The only questionable exogenous variables are the first three, but they can be adequately justified. Lebanon is a small, open economy with a monetary framework that pegs the exchange rate to the US Dollar, so effectively interest rates are set outside and are equal to international (US) rates plus a risk premium, and the same holds true for the net interest margin $\left(r-r_{0}\right) . \delta$, the cost to income ratio, is trickier to justify, but it is not widely off the mark to assume that Lebanese banks try to target $\delta$ at no more than $55 \%$. As to $\theta$, which primarily measures credit risk, it can safely be considered as predetermined, given that the portfolio of outstanding loans at Lebanese banks is non-tradable and securitization is largely frowned upon by BdL (Note 21). Note that $\theta$ is a direct and exact measure of credit risk, unlike other measures that try to capture credit risk in a more indirect way (Note 22).

We will regress ROAA on the above exogenous variables. The reason that we adopt ROAA is that it is a more rigorous regressand than ROAE, since it is does not disregard the higher risk associated with leverage, and it captures any regulation concerning financial leverage that is widely regarded as being pretty tough on Lebanese banks by BdL (Note 23). And the reason that we could regress ROAA against our set of exogenous or explanatory variables is that since ROAA $=\Pi / \mathrm{A}$ and since both $\mathrm{A}$ and the reduced-form equation for $\Pi$ are function of these exogenous variables, then ROAA is function of them as well. We can find the comparative statics results on ROAA to be as follows:

$$
\begin{aligned}
& R O A A=f\left(r-r_{o}, \delta, \theta, \alpha, \beta, \vartheta, \omega, \psi\right) \\
& +\quad-\quad-\quad-\quad+\quad+
\end{aligned}
$$

Theoretically, the justifications for the comparative static results in equation (7) can be readily captured. A higher net interest margin adds to profitability because it enhances operating income; whereas a higher cost-to-income ratio decreases operating income, and reduces profitability as a result; higher credit risk necessitates more capital so as to abide by the stipulated CAR, and hence increases interest income forgone that in turn eats into profitability; the same equally applies to a higher CAR and a higher ratio of liquid assets; a higher level of desired provisions reduces net income and consequently profitability; a higher $\omega$ allows banks to effectively free up capital, and hence to increase interest income and profitability; and, lastly, a higher ratio of non-interest income reflects successful diversification and more profitability. 
In the next section, we are going to estimate equation (7), which has been derived from solving the equation system identified by (1)-(6) and as a result is based on a theoretical but accurate depiction of Lebanese banks' profit maximization process. And, as argued earlier, it measures the impact on relative profitability of determinants that are only internal to the banks. We will also introduce a few dummy variables that capture important features that characterize the Lebanese banking system.

\section{Estimation Results}

We begin by outlining in Table (1) the descriptive statistics on all eight independent variables together with the dependent variable (ROAA) (Note 24). Note that all variables are in percent. In case of ROAA, the mean is $0.852 \%$ and the median is $0.895 \%$. Although the range is wide, around $21.72 \%$, the standard deviation is relatively low at $1.215 \%$. In case of the independent variables, the average and median interest rate spreads $(\mathrm{r}-$ $\mathrm{r}_{\mathrm{o}}$ ) are respectively $2.212 \%$ and $2.050 \%$. The cost-to-income ratio, $\delta$, has a mean of $63.40 \%$ and a median of $60.95 \%$. The standard deviation is close to the mean and median at $58.67 \%$. Credit risk $\theta$ ranges on average between $57.5 \%$ and $60.3 \%$, and has a relatively high standard deviation of $23.38 \%$. The capital adequacy ratio, $\alpha$, has a mean of $17.73 \%$ which is much higher than the median of $13.83 \%$ (Note 25). The distribution of this ratio is therefore skewed positively to the right. The liquidity ratio, $\beta$, varies widely between $2.65 \%$ and $99.73 \%$. Nonetheless, the standard deviation is relatively low at $13.24 \%$. The variable $\vartheta$ varies between zero, i.e. no loss provisions, to $195.68 \%$, i.e. a loan loss provision of almost double the amount of non-performing loans. The variable $\omega$, which relates non-performing loans to the capital base, varies between $16.64 \%$ and $128.55 \%$, with a mean of $58.75 \%$ and a median of $60.48 \%$. The standard deviation is relatively low at $27.98 \%$. The final variable $\psi$ is the ratio of non-interest income to total assets. It is relatively small, with a mean of $0.553 \%$ and a standard deviation of $0.404 \%$.

Table 1. Descriptive statistics

\begin{tabular}{lccccc}
\hline Variable & mean & median & maximum & minimum & Standard deviation \\
\hline ROAA & 0.85218 & 0.89500 & 10.7600 & -10.9600 & 1.21479 \\
$\left(\mathrm{r}-\mathrm{r}_{\mathrm{o}}\right)$ & 2.21214 & 2.05000 & 6.31000 & -0.7000 & 0.96591 \\
$\delta$ & 63.3945 & 60.9500 & 458.960 & -928.270 & 58.6765 \\
$\theta$ & 57.536 & 60.284 & 153.999 & 3.715 & 23.377 \\
$\alpha$ & 17.7330 & 13.8300 & 159.390 & 0.0000 & 16.6936 \\
$\beta$ & 32.1963 & 30.3350 & 99.730 & 2.64592 & 13.2423 \\
$\vartheta$ & 77.2166 & 81.7050 & 195.680 & 0.0000 & 23.0531 \\
$\omega$ & 58.755 & 60.477 & 128.554 & 16.638 & 27.979 \\
$\psi$ & 0.553 & 0.449 & 2.899 & 0.0000 & 0.404 \\
\hline
\end{tabular}

Table 2 presents the empirical results of regressing ROAA on the eight exogenous variables, and on a dummy variable for the year 2006, the year of the summer war with Israel. Three different panel estimation procedures are adopted: Ordinary Least Squares (OLS), fixed cross section effects, and random cross section effects. It was not possible to test for time effects, whether fixed or random. In the first case the reason is the presence of perfect collinearity, and in the second case because of the unbalanced nature of the data. What is noteworthy is that the coefficient estimates in the OLS estimation and in the random cross section effects are almost the same, although the standard errors, and by implication the t-statistics, are different. Another noteworthy aspect of the results is the low Durbin Watson statistics. Lastly, the panel least squares with fixed cross section effects boosts the R-squared from around $15 \%$ to around $40 \%$. A test on whether these fixed effects are redundant is rejected with a Chi-square statistic that has a p-value of less than 0.00005 , under the null hypothesis of no fixed effects. This is evidence of heterogeneity between the cross sections that stand for individual banks. The Hausman test for correlated random effects, between the fixed cross section effects and the random cross section effects, rejects the specification with random effects with a Chi-square statistic that takes a p-value of less than 0.00005 . And although the dummy variable is statistically significant in both the OLS specification and the panel least squares with random cross section effects, it is statistically insignificant in the model that was found superior to the above two, i.e. the panel least squares with fixed cross section effects. 
Table 2. Panel least squares of the return on average assets (ROAA) on eight exogenous variables

The number of observations is 391, 36 cross sections, and 12 periods (2003-2014)

\begin{tabular}{lccc}
\hline Regressor & Panel with Ordinary Least Squares & Panel with fixed cross section effects & Panel with random cross section effects \\
\hline Constant & $-1.05013(3.82917)$ & $-2.89944(7.49237)$ & $-1.05219(4.53091)$ \\
$\left(\mathrm{r}-\mathrm{r}_{\mathrm{o}}\right)$ & $0.27376(3.80195)$ & $0.83356(8.12696)$ & $0.27432(4.49681)$ \\
$\delta$ & $0.00227(2.59360)$ & $0.00418(5.34192)$ & $0.00228(3.08039)$ \\
$\theta$ & $0.00638(2.56712)$ & $0.00840(2.85634)$ & $0.00638(3.03416)$ \\
$\alpha$ & $0.00762(2.15934)$ & $0.01270(2.70947)$ & $0.00763(2.55374)$ \\
$\beta$ & $0.01557(3.23284)$ & $0.01055(1.96167)$ & $0.01553(3.81025)$ \\
$\vartheta$ & $0.00058(0.27101)$ & $0.00229(0.94745)$ & $0.00059(0.32377)$ \\
$\omega$ & $0.00295(1.43550)$ & $0.00138(0.73347)$ & $0.00295(1.69579)$ \\
$\psi$ & $-0.06340(0.39313)$ & $0.73876(3.13837)$ & $-0.06312(0.46205)$ \\
Dummy 2006 & $0.48125(2.55600)$ & $0.26008(1.59767)$ & $0.48087(3.01916)$ \\
Adjusted & 0.15425 & 0.39486 & 0.15436 \\
R-Squared & & & 1.04347 \\
Durbin-Watson & 1.04348 & 1.66611 & \\
\hline
\end{tabular}

Note. In parentheses are absolute t-statistics.

In what concerns the coefficient estimates, 5 out of 8 factors are found statistically significant in the OLS model and the panel least squares with random effects, and 6 out of 8 in the panel least squares with fixed cross section effects. It is remarkable to notice that all the signs of the estimated coefficients are positive except the coefficient on the non-interest income which is negative, but statistically insignificant, in two cases out of the three. In the superior model with fixed cross section effects this coefficient is positive and highly significant statistically. Finally, these results cannot be taken as truly as the results in Tables 3 and 4, because one variable is omitted from the analysis, which is the lagged dependent variable. It turns out that the inclusion of this variable alleviates the econometric anomaly of the presence of positive serial correlation in the residuals in the three models of Table 2.

In Table 3, four different models are estimated. The first is a panel least squares with OLS that includes the dummy for the year 2006. Since the latter turns out to have a statistically insignificant coefficient with a t-statistic of 0.76521 , it is dropped from the other three models. Thus, excluding the dummy, the second model is a panel least squares with OLS ; the third is a panel least squares with fixed cross section effects; and the fourth and last one is a panel least squares with random cross section effects. Similarly to Table 2, it was not possible to estimate a panel least squares with period fixed effects and period random effects for the same reasons as those mentioned above.

The coefficients on the lagged dependent variable in the four models are statistically significant with $\mathrm{t}$-statistics between 2.8292 and 4.2962. This shows that this variable should not be omitted from the analysis. The estimates of these coefficients range between 0.10866 and 0.15528 . All the adjusted R-Squares are higher than $40 \%$, especially the third model, with fixed cross section effects, that has the highest R-square of $47.63 \%$. Models 2 and 4 in Table 3 produce coefficients that are almost the same. But the standard errors and, by implication, the t-statistics differ. This is in conformity to the results in Table (2). The number of statistically significant coefficients falls after correction for serial correlation. Model 2 and Model 4 have the same significant variables at 3: the net interest spread, the cost to income ratio, and the capital adequacy ratio. Model 3 has 4 variables that enter statistically significantly in the regression. The first three variables are the same as the significant variables for Models 2 and 4, and the fourth additional variable is the non-interest income variable. 
Table 3. Panel least squares of the return on average assets (ROAA) on eight exogenous variables

The number of observations is 355, 36 cross sections, and 11 periods (2003-2014)

\begin{tabular}{|c|c|c|c|c|}
\hline Regressor & $\begin{array}{l}\text { Model 1: Panel with } \\
\text { Ordinary Least Squares }\end{array}$ & $\begin{array}{l}\text { Model 2: Panel with } \\
\text { Ordinary Least Squares }\end{array}$ & $\begin{array}{l}\text { Model 3: Panel with fixed } \\
\text { cross section effects }\end{array}$ & $\begin{array}{l}\text { Model 4: Panel with random } \\
\text { cross section effects }\end{array}$ \\
\hline Constant & $1.17009(4.17465)$ & $1.22828(4.55577)$ & $0.29238(0.55043)$ & $1.22828(4.78388)$ \\
\hline$\left(r-r_{o}\right)$ & $0.26737(4.40095)$ & $0.27149(4.48911)$ & $0.48093(4.31540)$ & $0.27149(4.71388)$ \\
\hline$\delta$ & $-0.02180(10.4535)$ & $-0.02195(10.5705)$ & $-0.02488(7.00927)$ & $-0.02195(11.0998)$ \\
\hline$\theta$ & $0.00024(0.14641)$ & $-0.00020(0.13123)$ & $-0.00022(0.13474)$ & $-0.00021(0.13937)$ \\
\hline$\alpha$ & $0.01384(4.59392)$ & $0.01413(4.72915)$ & $0.01156(2.51491)$ & $0.01413(4.96594)$ \\
\hline$\beta$ & $-0.00154(0.37364)$ & $-0.00223(0.55287)$ & $0.00760(1.51734)$ & $-0.00223(0.58055)$ \\
\hline$\vartheta$ & $0.00115(0.64303)$ & $0.00125(0.70075)$ & $0.00363(1.59143)$ & $0.00125(0.73583)$ \\
\hline$\omega$ & $0.00317(1.40554)$ & $0.00292(1.30959)$ & $0.00074(0.24241)$ & $0.00292(1.37516)$ \\
\hline$\psi$ & $-0.17706(1.32102)$ & $-0.17778(1.32722)$ & $0.56335(2.56457)$ & $0.17777(1.39367)$ \\
\hline Dummy 2006 & $0.11785(0.76521)$ & - & - & - \\
\hline $\operatorname{ROAA}(-1)$ & $0.15252(3.99833)$ & $0.15528(4.09131)$ & $0.10866(2.82922)$ & $0.15528(4.29616)$ \\
\hline Adjusted & & 0.42255 & & \\
\hline R-Squared & 0.42185 & & 0.47630 & 0.42255 \\
\hline Durbin-Watson & 2.00741 & 2.01504 & 2.40776 & 2.01504 \\
\hline
\end{tabular}

Note. In parentheses are absolute t-statistics.

A test whether Model 3 in Table 3 has redundant cross section fixed effects is rejected with a Chi-square that has a p-value of 0.0002. Hence, as we found above, there is heterogeneity in commercial banks in Lebanon. Also, a Hausman test for correlated random effects rejects the random cross section specification in favor of the fixed cross section specification, with a p-value lower than 0.00005 . Therefore the results support strongly the model with fixed cross section effects, i.e. Model 3.

A dummy variable was generated that takes the value 1 if the bank is an Alpha bank, and zero otherwise. This dummy variable was included as an interactive term with the eight regressors in Table 3 . The lagged variable was also included. If the coefficients on these eight interactive terms are jointly statistically significant then this is evidence that Alpha banks and non-Alpha banks behave differently. The null hypothesis that the eight interactive terms are zero fails to be rejected with F-statistics that have the following p-values: 0.3030 (OLS panel), 0.6202 (panel with fixed cross section effects), and 0.2725 (panel with random cross section effects). Hence, Alpha banks and non-Alpha banks behave similarly.

In addition, a dummy variable was generated that takes the value 1 if the bank is a listed bank on the Beirut Stock Exchange, and zero otherwise. This dummy variable was included in the same way as the previous dummy regarding the Alpha banks. The null hypothesis that the eight interactive terms are zero fails to be rejected with F-statistics that have the following p-values: 0.9456 (OLS panel), 0.9806 (panel with fixed cross section effects), and 0.9320 (panel with random cross section effects). As a result, listed and non-listed banks also behave similarly.

Table 4. Long-run effects of the panel least squares of the return on average assets (ROAA) on eight exogenous variables from Table 2

The number of observations is 355,36 cross sections, and 11 periods (2003-2014)

\begin{tabular}{lccc}
\hline Regressor & Panel with Ordinary Least Squares & $\begin{array}{c}\text { Panel with fixed cross section } \\
\text { effects }\end{array}$ & $\begin{array}{c}\text { Panel with random cross } \\
\text { section effects }\end{array}$ \\
\hline$\left(\mathrm{r}-\mathrm{r}_{\mathrm{o}}\right)$ & $0.32140(4.45623)$ & $0.53956(4.25998)$ & $0.32140(4.67935)$ \\
$\delta$ & $-0.02598(10.8956)$ & $-0.02791(7.00341)$ & $-0.02598(11.4411)$ \\
$\theta$ & $0.00346(1.31969)$ & $0.00083(0.24253)$ & $0.003456(1.3858)$ \\
$\alpha$ & $0.01673(4.46416)$ & $0.01297(2.43348)$ & $0.01673(4.68767)$ \\
$\beta$ & $-0.00264(0.55020)$ & $0.00853(1.53135)$ & $-0.00264(0.57775)$ \\
$\vartheta$ & $0.00148(0.69954)$ & $0.00407(1.58765)$ & $0.00148(0.73457)$ \\
$\omega$ & $-0.00024(0.13128)$ & $-0.00025(0.13479)$ & $-0.00024(0.13785)$ \\
$\psi$ & $-0.21045(1.31775)$ & $0.6320(2.59089)$ & $-0.21045(1.38373)$ \\
\hline
\end{tabular}

Note. In parentheses are absolute t-statistics. 
The coefficient estimates in Table 3 are short-run impacts. The long-run impacts are obtained by dividing the short-run coefficients in Table 3 by 1 minus the coefficient on the lagged dependent variable in the same Table. Hence, if this coefficient is positive and is less than +1 , the long-run impacts are higher than the short-run impacts. If this is the case, then economic theory, which predicts that adjustment is faster in the long run, is upheld. This is indeed the case. The long-run multipliers to the short run impacts are respectively 1.1838 (OLS panel), 1.1219 (panel with fixed cross section effects), and 1.1838 (panel with random cross section effects). Notably, the short-run and long-run impacts have necessarily the same signs. Table 4 reproduces these long-run impacts together with their t-statistics for the null that each impact is zero. The statistical significance, as measured by these t-statistics, differs only slightly between Table 3 and Table 4 . Of course, the model to adopt, and to base the analysis upon, is the panel least squares with fixed cross section effects, i.e. column 3 of Table 4 .

An F-test was carried out on the joint significance of the four variables that were found to be non-significant in the model in column 3 of Table 4 . The null hypothesis that all four coefficients on these four variables are zero fails to be rejected with actual p-values of 0.6131 (OLS panel), 0.2903 (panel with fixed cross section effects), and 0.5660 (panel with random cross section effects). Therefore, these four variables can be omitted from the regressions.

Having omitted these four variables the specification with the remaining four variables is estimated by both fixed period and fixed cross section effects. In this case the exact multicollinearity is avoided. The null hypothesis that all period fixed effects are zero fails to be rejected with an F-test that has a p-value of 0.3116. The null hypothesis that all cross section fixed effects are zero is rejected with an F-test that has a p-value of 0.0009 . Moreover, the Hausman test for correlated random effects of the specification with random cross section effects, relative to the specification with fixed cross section effects, has a chi-square value with a p-value of less than 0.00005. All these tests point to the same conclusion: the best restricted model is the model with fixed cross section effects. This applies too to the non-restricted model in Table 3, i.e. the one with cross section fixed effects.

Table 5 presents the results of estimating the panel least squares with fixed cross section effects without the four variables that were found to be insignificant in Tables 3 and 4. Since the model includes the lagged dependent variable, the short-run impacts are reproduced in column (2) of Table 5, and the long-run impacts in column (3) of Table 5. The multiplier to the long run is 1.1115 , i.e. $1 /(1-0.10031)$, where 0.10031 is the coefficient on the lagged dependent variable. The R-square in Table (5) is $49.192 \%$, higher than its equivalent in Table 3 of $47.630 \%$. Moreover, the Durbin Watson statistic is 2.05524, very close to the perfect value of 2.

The following impacts can be retrieved from Table 5. A $1 \%$ increase in the net interest rate spread increases ROAA by $0.6226 \%$ in the short run and by $0.6920 \%$ in the long run. A one standard deviation increase in the spread, equivalent to $0.966 \%$, will increase the ROAA by $0.668 \%$ in the long run. A $10 \%$ increase in the cost to income ratio, i.e. from $40 \%$ to $50 \%$, will reduce ROAA by around $0.10 \%$. A one standard deviation increase in the cost to income ratio, equivalent to $58.68 \%$, will decrease the ROAA by $0.59 \%$. A $1 \%$ increase in CAR will increase ROAA by around $0.01 \%$, or one basis point. A one standard deviation increase in CAR, equivalent to a change of $16.694 \%$, increases the ROAA by $0.1669 \%$. A $1 \%$ increase in the non-interest income will increase the ROAA by $0.401 \%$ in the short run and by $0.445 \%$ in the long run. A one standard deviation increase in the non-interest income, equivalent to $0.4 \%$, will increase the ROAA by $0.18 \%$ in the long run.

Table 5. Panel least squares of the return on average assets (ROAA) on four exogenous variables, with the lagged dependent variable

The total number of observations is 404, 38 cross sections, and 11 periods (2003-2014)

\begin{tabular}{lcc}
\hline Regressor & Panel with fixed cross section effects - short run & Panel with fixed cross section effects - long run \\
\hline Constant & $-0.29714(1.03913)$ & - \\
$\left(\mathrm{r}-\mathrm{r}_{\mathrm{o}}\right)$ & $0.62258(6.80227)$ & $0.69199(6.71342)$ \\
$\delta$ & $-0.00933(5.55616)$ & $-0.01037(5.62600)$ \\
$\alpha$ & $0.00862(2.24631)$ & $0.00958(2.17432)$ \\
$\psi$ & $0.40045(2.11798)$ & $0.44510(2.12668)$ \\
ROAA(-1) & $0.10031(2.63535)$ & - \\
Adjusted R-squared & 0.49192 & \\
Durbin-Watson & 2.05524 & \\
\hline
\end{tabular}

Note. In parentheses are absolute t-statistics. 
In the following section, we are going to evaluate the above results in relation to the theoretical model given by equation (7) and in comparison to the results found in the literature. We will also be identifying some of the peculiar features that characterize Lebanese banking that can help us explain our results.

\section{Evaluation of Results}

Rigorous estimation and testing have yielded the formulation with fixed cross section effects as the most robust model, rightly indicating the heterogeneity and significant differences among banks in Lebanon. It is interesting that within this model, the dummy variable for the 2006 war was insignificant. This is because the war lasted for one month (July) only, and the banking system was able to overcome with strides this short-run hiccup, as also evidenced by the model's ability for potent long-run adjustments. In this sense, it is persistent political instability, such as the one that the country has been experiencing since 2011, that is testing the banks' performance and their ability to maintain sustained profitability.

Another interesting result is the insignificance of the dummy variables for the large Alpha banks and for the listed banks. The reason behind the insignificance of the Alpha banks is that while they do have higher profits than other smaller banks, the latter do have smaller assets, thus rendering the ROAA for each group of banks fairly the same. As to the insignificance of the listed banks, the reasoning is perhaps a bit more subtle. Listed banks do indulge in decent corporate governance practices and are subject to vigilant shareholders' scrutiny, which should keep banks on "their toes" and induce them to deliver good returns, but the Beirut Stock Exchange is small and rather inefficient, characterized by thin trading and the absence of institutional investors, not to mention the persistence of ownership of voting stocks by the main families (Note 26). As a result, the ROAAs of listed banks seem to be not all that different from unlisted ones.

Also important, of course, are the results concerning the exogenous variables of the model of fixed cross section effects in Table 3. Four of these variables were insignificant: credit risk $\theta$, and the ratio of non-performing loans to capital $\omega$, and each with the right sign; the ratio of liquid assets $\beta$, and the ratio of provisions to non-performing loans $\vartheta$, but each with the opposite sign. As to $\theta$, though Lebanese banks can be risk takers with an average risk weight of $57 \%$, almost $11 \%$ of their assets are in Lebanese Pound treasury bills which are not subject to risk weights but generate good yields (Note 27). So this tends to neutralize the effect of $\theta$ on profitability, and for good reasons. Note that this finding of ours is in disagreement with the positive significant result obtained by Hakim and Neaime (2001) and the negative significant result found by Saad and El-Moussawi (2012). Concerning $\omega$, its insignificance mainly arises from the fact that BdL is always coaxing banks to settle their NPLs so as to maintain a healthier balance sheet, and in the process such measures render its effect on profitability rather negligible (Note 28 ). In relation to $\beta$, its insignificance is the product of two opposing tendencies: on the one hand, it should lead to less interest income and profitability, but on the other hand it should add to more confidence in the banks and hence to more business and profitability (Note 29). And, incidentally, this result conforms to the result obtained by Hakim and Neaime (2011). Lastly, regarding $\vartheta$, the fact that it has an insignificant result is an indication that Lebanese banking - prodded by BdL - seems to engage in dynamic provisioning: given the cyclical nature of credit losses, banks build up provisions in good times to be drawn on in economic downturns as losses increase (Note 30). This tends to weaken the impact of provisions on profitability and render them neutral.

More importantly, we have derived in Table 5 that the fundamental determinants of ROAA in Lebanese banking can be reduced to four significant exogenous variables: net interest margin, capital adequacy, cost-to-income, and non-interest income. All four have the expected sign except for capital adequacy. The net interest margin averages about $2.2 \%$, which is relatively low because of the tough competition among Lebanese banks, but stands to increase in the near future with higher US rates (and perhaps more consolidation in the banking system) (Note 31). As to the capital adequacy ratio, it has an average of $17.7 \%$ and its distribution is tilted to the right towards higher ratios. The fact that it exhibits a positive relation with ROAA is quite impressive, indicating that banks reap more returns from holding additional capital than they lose in forgone interest, as reflected in their ability to access capital and deposits at a lower cost and in their potential to extend more and bigger loans. It is also a result that is in harmony with the result in Saad and El-Moussawi (2012). The cost-to-income ratio has the expected negative effect on profitability, but it averages a high $63.4 \%$, driven largely by the cost of a large branch network, higher expenditures on compliance and information technology (IT), and more foreign expansion (Note 32). However, in the medium-tem this ratio is expected to fall as IT starts to substitute for branches and as compliance and expansion costs subside with more maturity. The last variable, non-interest income, reflects the increasing universality of Lebanese banks and their march to become full-service banks. It averages $0.5 \%$ and is bound to increase as Lebanese banks diversify more into investment and private banking and into asset and wealth management, and as these latter activities generate higher margins than interest 
operations. Perhaps more crucially, what these four variables signify is that, when it comes to profitability, what matters most are still the essential aspects that guarantee successful banking in a well-regulated and supervised-system: a good interest margin, an ample capital adequacy, a cost-efficient organization, and a diversified spectrum of activities.

In the next and last section, we will summarize our findings, and reflect on what the results imply for banks and the monetary authorities, in how they should design their strategies and policies to maintain a healthy and profitable Lebanese banking system.

\section{Conclusion}

Since the new millennium, the Lebanese financial sector's sound contribution to GDP has been steadily maintained at an annual average of 7\%. However, the prospects of its relative profitability growth have been dampened by the perils of its geopolitical surroundings. This has in more ways than one battle-hardened the banking sector that has weathered a basket of adverse challenges, both economic and political.

Within this context, the few published papers studying the determinants of profitability in the Lebanese banking sector have been researched on an ad hoc basis by analyzing a mix of bank-specific, macroeconomic, and industry-related variables. This paper adopts a simple yet constrained profit maximization model that regresses the more versatile Return on Average Assets (ROAA) measure against eight exogenous variables: net interest margin, cost to income, credit risk, capital adequacy, liquidity, provisions, non-performing loans, and non-interest income. The estimations are carried across a panel data of 39 commercial banks spanning the period 2003-2014. Out of the three different formulation panels employed, namely the Ordinary Least Squares, Random Cross Section and Fixed Cross Section Effects, the latter proves to be the most prevailing, reflecting heterogeneity among Lebanese banks. Moreover, further evaluation confirms that net interest margin, cost to income, capital adequacy, and non-interest income as the four significant variables determining ROAA, and with the right corresponding signs except for capital adequacy. From a Lebanese banking perspective, the four variables can be rationalized to represent the backbone of profitability. For, net interest margin at an average of $2.2 \%$, remains the bread and butter of commercial banking, with the successful forthcoming increases in interest rate spreads. Equally, efficiently amortizing fixed and IT investment expenses over time is likely to compress the $63.4 \%$ average of the cost-to- income ratio and shore up profitability. The "controversial" positive sign of the average of the capital adequacy ratio at $17.7 \%$ nullifies the opportunity cost of forgoing interest on excess capital by enabling banks to attract and extend capital at favorable terms. Finally, at $0.5 \%$, the average ratio of non-interest income to assets reflects the direction of undertaking nontraditional Lebanese banking activities relevant to fees and commissions that originate in investment banking, wealth and asset management.

The last point above could perhaps set the course on where Lebanese banks ought to concentrate in generating more alternative profits. Having almost saturated their traditional commercial banking revenue sources, banks in Lebanon need to start nurturing their fee-generating activities by actively developing investment banking, wealth management, and fund-engineering lines of businesses and services. At less than half the emerging markets average of $1.13 \%$ in non-interest income to assets, Lebanese banks are presented with an opportunity to capitalize on in these services (Note 33). However, this will require a supportive regulatory environment, which brings to light the role of the regulator and monetary authorities in creating the required framework for such activities. With a market cap-to-GDP of $21 \%$ compared to $40 \%$ for MENA banks, the local capital market has some way to go. But hopefully with the recent establishment of the Capital Markets Authority, things might be starting to move in the right direction. And certainly, an uptake in M\&As within banks and their associated future benefits will lend a helping hand to better rationalization of Lebanese banking activities and to more rigorous capital market developments.

\section{Acknowledgement}

The opinions and comments of the authors of this paper represent their own views and not necessarily those of Blominvest Bank. The usual disclaimer about remaining errors applies. We are grateful for the excellent research assistance of Chris Avedis Kouyoumjian.

\section{References}

Azar, S., \& Kouyoumjian, C. V. (2016). Impact of internal and external factors on the short run and the long run profitability of commercial banks in Lebanon. European Journal of Business and Management, 8(8), 12-24.

Bankdata. (Various Years). Bilanbanques. Bankdata Financial Services. Beirut, Lebanon.

Dietrich, A., \& Wanzenried, G. (2009). What Determines the Profitability of Commercial banks? New Evidence from Switzerland. Institute of Financial services IFZ, LucerneUniversity of Applied Sciences. 
Flamini, V. et al. (2009). The Determinants of Commercial Bank Profitability in Sub-Saharan Africa. IMF Working Papers WP/09/15. http://dx.doi.org/10.5089/9781451871623.001

Hakim, S., \& Neaime, S. (2001). Performance and Credit Risk in Banking: A Comparative Study for Egypt and Lebanon. ERF Working Paper 0137.

Ho, T., \& Saunders, A. (1981). The Determinants of Bank Interest Margins: Theory and Empirical Evidence. Journal of Financial and Quantitative Analysis, 16, 581-600. http://dx.doi.org/10.2307/2330377

Mouradian, A. (2016). M\&As in the Lebanese Banking Sector, 1993-2014: Determinants and Performance. Unpublished Report.

Peters, D. et al. (2004). The Performance of Banks in Post-War Lebanon. International Journal of Business, 3(2).

Saad, W., \& El-Moussawi, C. (2012). The Determinants of Net Interest Margins of Commercial banks in Lebanon. Journal of Money, Investment, and Banking, 23.

Salloum, A., \& Hayek, J. (2012). An Analysis of the Determinants of Commercial Banks Profitability in Lebanon. International Research Journal of Finance and Economics, 93.

Shareholders' Rights. (2015). Lebanon: Governance and Integrity Report. Capital Concepts: Beirut, Lebanon.

Trujilo-Ponce, A. (2013). What Determines the Profitability of banks from Spain? Working Paper, Department of Business Administration, Pablo de Qlavide University.

\section{Notes}

Note 1. For more on the performance of banks in post-war Lebanon, see Peters et al. (2004).

Note 2 . The corresponding rates for emerging countries are $2 \%$ and $17 \%$.

Note 3. At end of 2015, banks in Lebanon had assets of $\$ 186$ billion, private deposits of $\$ 152$ billion, capital of $\$ 16.7$ billion, and loans to the private sector of $\$ 54.3$ billion, the latter equal to more than $100 \%$ of GDP.

Note 4. For instance, during the period 2003-2014, deposits grew at more than 12\% between 2003 and 2010 but at only half of that between 2011 and 2014.

Note 5. For a concise literature review on these determinants, see Trujillo-Ponce (2013) and Dietrich and Wanzenried (2009).

Note 6. The relationship with inflation is interesting, since it argues that banks can largely anticipate inflation and adjust their interest rates in a way that increases their lending rates faster than their deposit rates.

Note 7. There is, of course, the "too big to fail" argument, but this also produces an indeterminate effect of bank size on profitability, since on one hand it would require from big banks lower profits but on the other hand it would serve as a catalyst for considerable cost advantages.

Note 8. A similar paper by Salloum and Hayek (2012) find both NIM and ROAA to exhibit the same relations with these variables.

Note 9. Interestingly, they also extend their work to banks' net worth and find it to be determined by the same set of variables in addition to net income.

Note 10. Saad and El-Moussawi (2012) argue that their findings are based on the dealership model of Ho and Saunders (1981), but there is no explicit analytical connection between that model and the regression with internal and external determinants that they estimate.

Note 11. A good example is NIM, where in some formulations it is an endogenous, dependent variable, while in others it is an exogenous, independent variable.

Note 12. For instance, the amended Basel III Accord (after the financial crisis of 2008) gives special significance to liquidity and leverage, besides a renewed emphasis on capital adequacy.

Note 13. The banks are all private: 26 are Lebanese-owned, 5 are Lebanese with Arab control, 4 are Arab banks, and 4 are foreign banks. All these are the commercial banks (out of 54) whose full data are available for the 2003-2014 period. This period is chosen because it corresponds to the "maturing" phase for Lebanese banks after the first and most intensive post-war consolidation of the sector was completed in 2003 - see Mouradian (2016).

Note 14. LIQ is primarily composed of cash, deposits at the Central Bank, and deposits at international banks; I is mostly composed of investments in treasury bills and government Eurobonds; and $\mathrm{L}$ is loans to the private 
sector.

Note 15 . More than $80 \%$ of liabilities at Lebanese banks are made up of private deposits.

Note 16. NII is usually comprised of net fees and commissions, net income on foreign exchange, and net gain/loss on financial assets or investments. We will include only net fees and commissions in our model since it reflects true diversification into fee-generating activities like asset management and private and investment banking.

Note 17. Of this "mandated" liquidity, banks are required to maintain at BdL $10 \%$ of their foreign currency deposits in liquid assets and $15 \%$ as remunerated foreign currency deposits.

Note 18. This coverage ratio excludes real guarantees and collaterals.

Note 19. It is also evidenced by BdL's frequent calls on banks to settle their NPL and to avoid carrying excessive doubtful loans against their capital.

Note 20. The constrained maximization equation is as follows: $\Pi=(\mathrm{r}-\mathrm{ro})(\mathrm{A}-\mathrm{C})+\mathrm{NII}-(\mathrm{r}-\mathrm{ro}) \mathrm{LIQ}-\left(\mathrm{P}^{*}-\mathrm{P}\right)$ $-\delta\left\{(\mathrm{r}-\mathrm{ro})(\mathrm{A}-\mathrm{C})+\mathrm{NII}-(\mathrm{r}-\mathrm{ro}) \mathrm{LIQ}-\left(\mathrm{P}^{*}-\mathrm{P}\right)\right\}+\lambda_{1}(\mathrm{C} / \theta \mathrm{A}-\alpha)+\lambda_{2}(\mathrm{LIQ} / \mathrm{A}-\beta)+\lambda_{3}\left(\mathrm{P}^{*} / \mathrm{NPL}-\vartheta\right)+\lambda_{4}(\omega-$ $\mathrm{NPL} / \mathrm{C})+\lambda_{5}(\mathrm{NII} / \mathrm{A}-\psi)$, where $\lambda_{1}-\lambda_{5}$ are the respective Lagrange multipliers for the five constraints.

Note 21. For more on this point, see Flamini et al (2009).

Note 22. Such measures were invariably like the ratios of loans to deposits or of loan-loss provisions to total loans.

Note 23. BdL's preference is for higher equity to assets ratios, notably in excess of $8 \%$.

Note 24. All data were compiled from Bankdata (Various Years).

Note 25. Note that the descriptive statistics for the capital adequacy ratio relate to Basel II figures, whereas the minimum of $12 \%$ discussed earlier relates to (the much tougher) Basel III and was set by BdL for 2015.

Note 26. See Shareholders Rights (2015).

Note 27 . Another $10 \%$ of assets are held in Lebanese Eurobonds, which are subject to risk weights, making total bank holdings of government debt equal to $21 \%$ of assets or close to $55 \%$ of government debt.

Note 28. In effect, NPLs as a ratio of total loans declined during the studied period 2003-2014 from more than 8\% to $3.5 \%$.

Note 29. Not to mention that liquidity parked at BdL earned in 2015 an average of $2.78 \%$ for US\$ deposits and 2.92\% for Lebanese Pound deposits

Note 30. Close to the system adopted in Spain - see Trujillo-Ponce (2013).

Note 31. The Hirschman-Hilfendahl Index (HHI) for concentration of Lebanese banking assets can be calculated as 724 , less than 1,000 , thus indicating a competitive market.

Note 32. For instance, in 2015 there was close to 1,100 branches in the country, or a branch for each 4,000 individuals, one of the highest ratios in emerging countries. There are additionally 17 Lebanese banks present in 31 foreign countries with a branch network exceeding 400 branches.

Note 33. As per footnote 16, the ratio of non-interest income to assets is confined to the fees and commissions component of non-interest income.

\section{Copyrights}

Copyright for this article is retained by the author(s), with first publication rights granted to the journal.

This is an open-access article distributed under the terms and conditions of the Creative Commons Attribution license (http://creativecommons.org/licenses/by/3.0/). 